\title{
Glypican-1 is a novel immunohistochemical marker to differentiate poorly differentiated squamous cell carcinoma from solid predominant adenocarcinoma of the lung
}

\author{
Yuichiro Kai ${ }^{1,2}$, Vishwa Jeet Amatya ${ }^{1}$, Kei Kushitani ${ }^{1}$, Takahiro Kambara ${ }^{1}$, Rui Suzuki ${ }^{1}$, Yutaro Fujii ${ }^{1}$, \\ Yasuhiro Tsutani ${ }^{2}$, Yoshihiro Miyata ${ }^{2}$, Morihito Okada ${ }^{2}$, Yukio Takeshima ${ }^{1}$ \\ ${ }^{1}$ Department of Pathology, Hiroshima University Graduate School of Biomedical and Health Sciences, Hiroshima, Japan; ${ }^{2}$ Department of Surgical \\ Oncology, Research Institute for Radiation Biology and Medicine, Hiroshima University, Hiroshima, Japan \\ Contributions: (I) Conception and design: Y Kai, VJ Amatya, Y Takeshima; (II) Administrative support: Y Miyata, M Okada, Y Takeshima; (III) \\ Provision of study materials or patients: Y Kai, Y Tsutani, Y Miyata, M Okada; (IV) Collection and assembly of data: Y Kai, VJ Amatya, K Kushitani, \\ Y Tsutani, Y Miyata, M Okada, Y Takeshima; (V) Data analysis and interpretation: Y Kai, VJ Amatya, K Kushitani, T Kambara, R Suzuki, Y Fujii; (VI) \\ Manuscript writing: All authors; (VII) Final approval of manuscript: All authors. \\ Correspondence to: Yukio Takeshima, MD, PhD. Department of Pathology, Hiroshima University Graduate School of Biomedical and Health Sciences, \\ 1-2-3 Kasumi, Minami-ku, Hiroshima 734-8551, Japan. Email: ykotake@hiroshima-u.ac.jp.
}

Background: The histological classification of non-small cell lung cancer (NSCLC) is essential in determining new cancer-specific targeted therapies. However, the accurate typing of poorly differentiated is difficult, particularly for poorly differentiated squamous cell carcinoma and adenocarcinoma of the lung with limited immunohistochemical markers. Thus, novel immunohistochemical markers are required. We assumed the possibility of the immunohistochemical expression of glypican-1 in lung squamous cell carcinoma.

Methods: The microarray dataset GSE43580 from Gene Expression Omnibus database were analyzed for confirming the gene expression of glypican-1 in lung squamous cell carcinoma. We immunohistochemically investigated the use of glypican-1 as a novel positive diagnostic marker for lung squamous cell carcinoma. Glypican-1 expression in 63 cases of poorly differentiated lung squamous cell carcinoma and 60 cases of solid predominant lung adenocarcinoma was investigated by immunohistochemistry. Additionally, we compared glypican-1 expression with the expressions of p40, cytokeratin 5/6, thyroid transcription factor-1 (TTF-1), and napsin A.

Results: All 63 cases of lung squamous cell carcinoma showed glypican-1 expression. In contrast, only 2 cases of lung adenocarcinoma showed glypican-1 expression. The sensitivity, specificity, and diagnostic accuracy of glypican-1 expression for differentiating lung squamous cell carcinoma from lung adenocarcinoma were $100 \%, 96.7 \%$, and $98.4 \%$, respectively. These were similar to those of p40 and significantly better than those of CK $5 / 6$.

Conclusions: We recommend the use of glypican-1 as an additional positive marker of lung squamous cell carcinoma.

Keywords: Glypican-1; immunohistochemistry; lung squamous cell carcinoma; lung adenocarcinoma

Submitted Jul 16, 2020. Accepted for publication Dec 10, 2020.

doi: $10.21037 /$ tlcr-20-857

View this article at: http://dx.doi.org/10.21037/tlcr-20-857 


\section{Introduction}

Lung cancer was the most common cancer in 2018 (2.09 million cases) and the leading cause of cancer death (1.76 million deaths) (1). Non-small cell lung cancer (NSCLC) accounts for approximately $85 \%$ of all lung cancers (2), of which lung adenocarcinoma and lung squamous cell carcinoma are the most common. An individualized approach, including immunotherapy and targeted therapy, is the standard treatment strategy for patients with lung adenocarcinoma and lung squamous cell carcinoma (3). Specific therapies can be offered to patients based on the histological and molecular status of primary tumors. Therefore, an accurate differentiation between lung adenocarcinoma and lung squamous cell carcinoma has become increasingly indispensable.

Lung squamous cell carcinoma typically shows keratinization and intercellular bridges by histopathological examination, and, in typical cases, the diagnosis of lung adenocarcinoma and lung squamous cell carcinoma is not difficult based on hematoxylin and eosin staining $(4,5)$. However, poorly differentiated lung squamous cell carcinoma without definite keratinization needs immunohistochemistry for its accurate diagnosis (6). The current immunohistochemical markers of lung squamous cell carcinoma is p40 and cytokeratin 5/6 (CK 5/6), and that of lung adenocarcinoma are thyroid transcription factor-1 (TTF-1) and napsin A $(4,5,7)$. Bishop et al. have recently reported the antibody $\mathrm{p} 40$, which targets a short isoform of $\mathrm{p} 63$, as a better positive marker of lung squamous cell carcinoma (8). This study showed that $\mathrm{p} 40$ has $100 \%$ sensitivity and $98 \%$ specificity for differentiation of lung squamous cell carcinoma from lung adenocarcinoma. Kriegsmann et al. have reviewed p40 as the best marker for diagnosing lung squamous cell carcinoma (9). However, even $\mathrm{p} 40$ immunostaining is not completely specific for lung squamous cell carcinoma considering that Affandi et al. (10) and Mawas et al. (11) reported a $77 \%$ sensitivity and a $90 \%$ specificity for lung squamous cell carcinoma, respectively. Thus, the search for novel immunohistochemical markers to assist in the accurate differentiation between lung adenocarcinoma and lung squamous cell carcinoma is still necessary. We previously reported glypican-1 as a novel positive marker of epithelioid mesothelioma, and its expression was also observed in the basal cells of the bronchial epithelium (12). Considering that the expressions of p40, CK 5/6, and p63 in lung squamous cell carcinoma were also observed in the basal cells of the bronchial epithelium (13), the possibility of the immunohistochemical expression of glypican-1 in lung squamous cell carcinoma was assumed. In order to confirm the gene expression of glypican-1 in lung squamous cell carcinoma, the microarray dataset was downloaded from the Gene Expression Omnibus (GEO) database and analyzed. Then, we evaluated the clinical applicability of glypican-1 as a diagnostic marker differentiating lung squamous cell carcinoma from lung adenocarcinoma. We present the following article in accordance with MDAR reporting checklist (available at http://dx.doi.org/10.21037/tlcr-20-857).

\section{Methods}

\section{Analysis of the Gene Expression Data}

The microarray data was downloaded from the GEO datasets (14). The GSE43580 contains the profiles of 150 NSCLC tumors, including 73 lung squamous cell carcinoma and 77 lung adenocarcinoma. We analyzed this data using the Subio Platform software (Subio, Amami-shi, Japan) and investigated the differentially expressed genes, on the basis of those that showed more than a 6-fold change.

\section{Patients and histological samples}

We retrieved the surgical specimens of 63 poorly differentiated lung squamous cell carcinoma and 60 solid predominant lung adenocarcinoma from the tissue archives of the Department of Pathology, Hiroshima University. Poorly differentiated lung squamous cell carcinoma included focal squamous differentiations (keratinization and/or intercellular bridge) or is less apparent in those, as defined in the WHO 2015 criteria (5).

All cases were reviewed by four pathologists (YK, KK, VJA, and YT). Histological findings and immunohistochemical marker panels were used to reclassify according to the 2015 World Health Organization histologic classification of lung tumors $(4,5)$. If there were disagreements in pathological diagnosis, the pathological records were reviewed, and a consensus was reached after discussion.

\section{Immunobistochemical procedures and evaluation}

Immunohistochemistry was performed on $3-\mu \mathrm{m}$ tissue sections from the best representative formalin-fixed paraffin-embedded tissue samples of lung squamous cell carcinoma and lung adenocarcinoma. Immunohistochemical 
staining of glypican-1 was performed using the Ventana BenchMark GX immunohistochemical autostainer (Roche Diagnostics, Tokyo, Japan) with an ultraView Universal DAB Detection Kit (Roche Diagnostics) as a detection system. Cell condition buffer 1 (Roche Diagnostics) was used for antigen retrieval at $99{ }^{\circ} \mathrm{C}$ for $60 \mathrm{~min}$. Sections were incubated with anti-glypican-1 antibody (rabbit-polyclonal, 1:250, Proteintech, Cat\# 16700-1-AP, RRID: AB_1851168) as the primary antibody for $40 \mathrm{~min}$ at room temperature. Immunohistochemistry staining of p40 (clone: BC28), CK 5/6 (clone: D5/16 B4), TTF-1 (clone: 8G7G3/1), and napsin A (clone: MRQ-60) was performed according to the protocol of a previous publication (11).

\section{Statistical analysis}

Cytoplasmic staining (glypican-1, CK 5/6, and napsin A) and nuclear staining (p40 and TTF-1) were considered positive. The positive grade was scored as $1+$ for up to $10 \%, 2+$ for $10 \%-50 \%$, and $3+$ for $>50 \%$ of the tumor cells showing positive immunostaining. Positive reactivity of the bronchial and bronchiolar epithelium was used as a positive control for glypican-1. The sensitivity, specificity, and diagnostic accuracy rates were calculated for each marker.

\section{Ethics statement}

This study was performed in accordance with the declaration of Helsinki (as revised in 2013). This study was conducted in accordance with the "Ethics Guidelines for Human Genome/Gene Research" enacted by the Japanese government and approved by the institutional ethics review committee (Hiroshima University E-1347).

\section{Results}

\section{Differential Gene Expression in lung squamous cell carcinoma and lung adenocarcinoma}

Among 150 cases in the GSE43580 (14), we picked up well stratified cases of 37 lung squamous cell carcinoma and 38 lung adenocarcinoma by supervised hierarchical clustering. Of the 703 statistically significant mRNA transcripts expressed, with a greater than 6-fold change, between lung squamous cell carcinoma and lung adenocarcinoma, 352 were upregulated in lung squamous cell carcinoma and 351 were upregulated in lung adenocarcinoma (Figure $1 A$ ). One GPC1 transcript, codes the glypican-1, was upregulated in lung squamous cell carcinoma (Figure 1B).

\section{Immunobistochemical results}

The expression scores of glypican-1 and the other markers of lung squamous cell carcinoma and lung adenocarcinoma are summarized in Table 1. Representative immunohistochemical staining for lung squamous cell carcinoma and lung adenocarcinoma are shown in Figures 2,3, respectively.

\section{Glypican-1 expression}

Glypican-1 expression was observed in the cytoplasm of the tumor cells and the basal cells of a normal bronchial and bronchiolar epithelium as an internal positive control. All $63(100 \%)$ cases of lung squamous cell carcinoma showed strong positivity for glypican-1 expression. Among them, a total of 61 and 2 cases showed $3+$ and $2+$ immunohistochemical scores, respectively. Conversely, only 2 cases $(3.3 \%)$ of lung adenocarcinoma were positive and the intensity was weak.

\section{Expressions of p 40 and cytokeratin 5/6}

The expressions of p40 were observed in all lung squamous cell carcinoma cases. Out of the 63 cases, 60 showed a $3+$ immunohistochemical score and 3 showed $2+$ immunohistochemical score. CK 5/6 expression was observed in 62 of 63 lung squamous cell carcinoma cases with immunohistochemical score of $3+$ in 54, 2+ in 6 and $1+$ in 2 cases.

In lung adenocarcinoma, the expressions of p40 and CK 5/6 were observed in 5 (8.3\%) and 10 (16.6\%) cases, respectively.

\section{Expressions of TTF-1 and napsin $A$}

The expressions of TTF-1 and napsin A were not observed in $59(93.7 \%)$ and $61(96.8 \%)$ lung squamous cell carcinoma cases, respectively.

In lung adenocarcinoma, the positive expressions of TTF-1 and napsin A were observed in 54 (90.0\%) and 49 $(81.6 \%)$ cases, respectively.

\section{Sensitivity, specificity, and diagnostic accuracy of glypican-1 and other immunobistochemical markers}

The sensitivity, specificity, and diagnostic accuracy of immunohistochemical markers differentiating lung squamous 

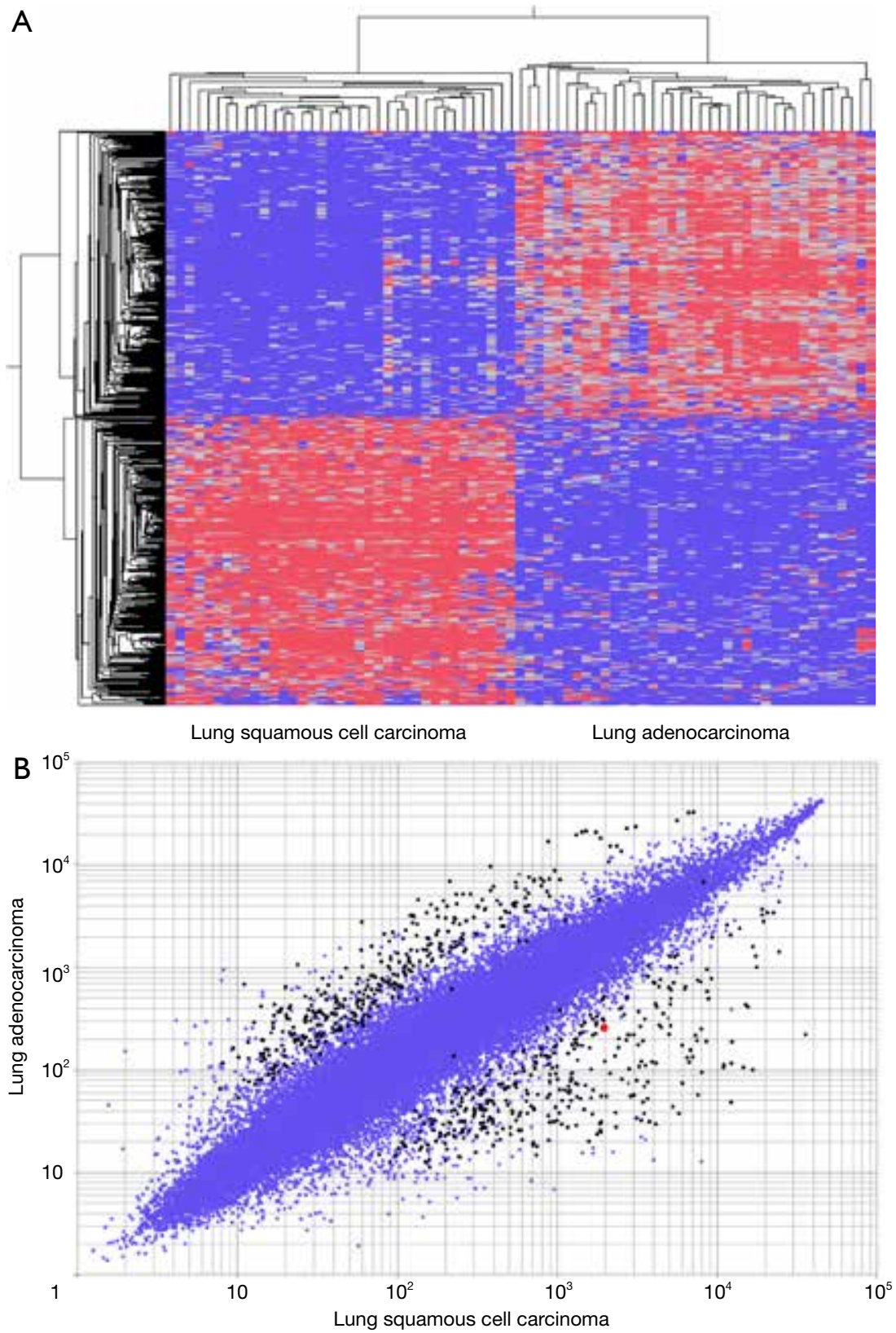

Figure 1 Gene expression analysis. (A) Supervised hierarchical clustering of 37 lung squamous cell carcinoma and 38 lung adenocarcinoma. Seven hundred three transcripts are differentially expressed by 6-fold change between lung squamous cell carcinoma and lung adenocarcinoma showing 352 upregulated in lung squamous cell carcinoma and 351 upregulated in lung adenocarcinoma. (B) Scatter plot diagram of differential expression of 703 transcripts, shown as black dots, between lung squamous cell carcinoma and lung adenocarcinoma. One transcript of GPC-1, shown as red dot, is upregulated in lung squamous cell carcinoma compared to that in lung adenocarcinoma. Blue dots represent all 54,613 transcripts in this microarray dataset. 
Table 1 Immunohistochemical findings for lung squamous cell carcinoma and lung adenocarcinoma

\begin{tabular}{|c|c|c|c|c|c|c|c|c|c|c|}
\hline \multirow{2}{*}{ Marker } & \multicolumn{5}{|c|}{ Lung squamous cell carcinoma } & \multicolumn{5}{|c|}{ Lung adenocarcinoma } \\
\hline & $\begin{array}{l}\text { Number of positive } \\
\text { cases }(\%)\end{array}$ & 0 & $1+$ & $2+$ & $3+$ & $\begin{array}{c}\text { Number of positive cases } \\
(\%)\end{array}$ & 0 & $1+$ & $2+$ & $3+$ \\
\hline Glypican-1 & 63/63 (100\%) & 0 & 0 & 2 & 61 & $2 / 60(3.3 \%)$ & 58 & 2 & 0 & 0 \\
\hline $\mathrm{p} 40$ & 63/63 (100\%) & 0 & 0 & 3 & 60 & $5 / 60(8.3 \%)$ & 55 & 5 & 0 & 0 \\
\hline TTF-1 & $4 / 63(6.3 \%)$ & 59 & 3 & 1 & 0 & $54 / 60(90.0 \%)$ & 6 & 3 & 5 & 46 \\
\hline Napsin A & $2 / 63(3.2 \%)$ & 61 & 2 & 0 & 0 & $49 / 60(81.6 \%)$ & 11 & 7 & 3 & 39 \\
\hline
\end{tabular}

${ }^{\dagger}$, 0: negative; $1+:<10 \%$ positive; $2+: 10 \%$ to $50 \%$ positive; $3+:>50 \%$ positive. CK, cytokeratin; TTF-1, thyroid transcription factor-1.
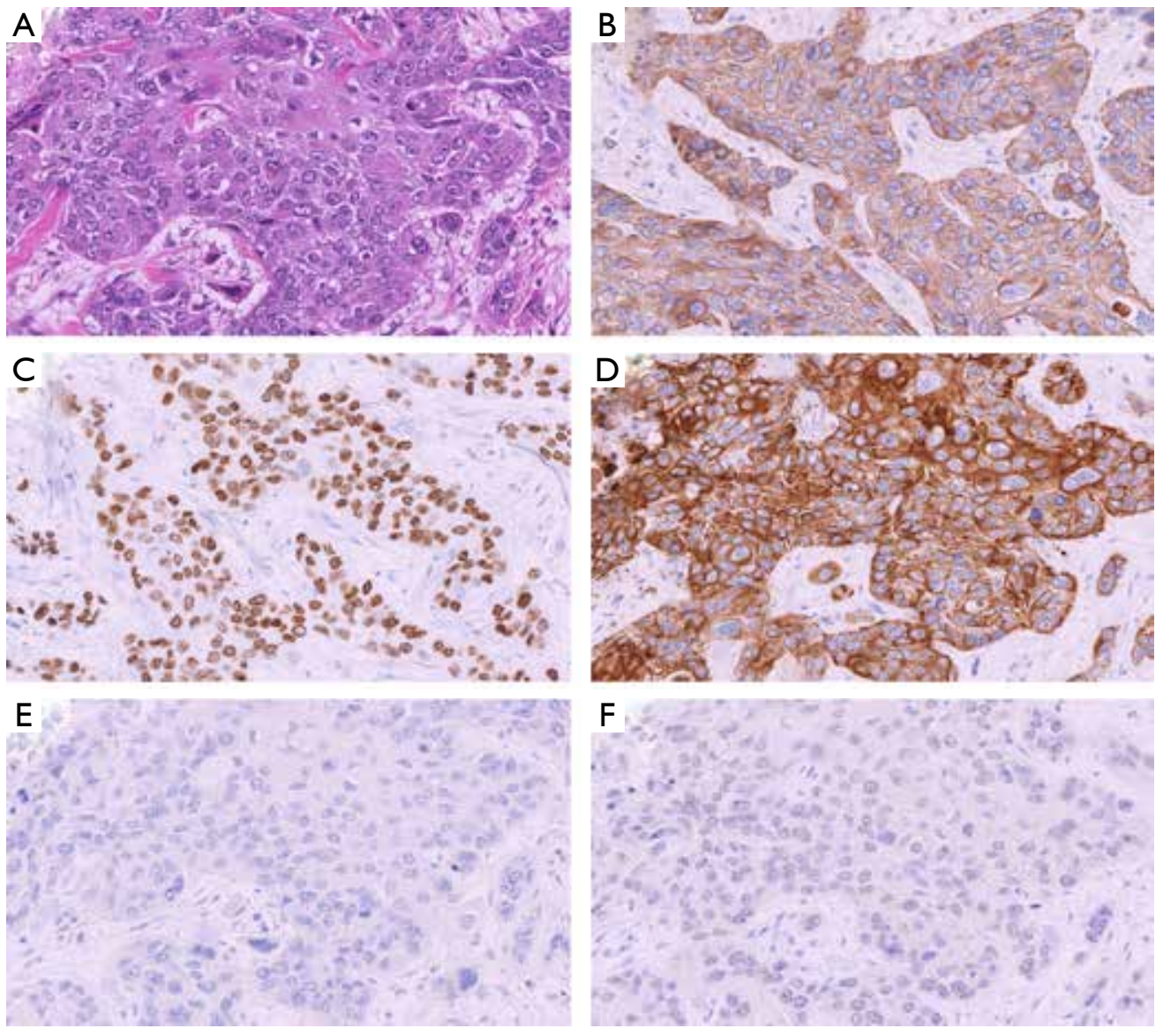

Figure 2 Representative immunohistochemical staining for poorly differentiated lung squamous carcinoma (A). The tumor cells were immunohistochemically stained positive for glypican-1 (B), p40 (C), and cytokeratin 5/6 (D) but were negative for thyroid transcription factor-1 (E) and napsin A (F) (hematoxylin and eosin $\times 200$ ). 

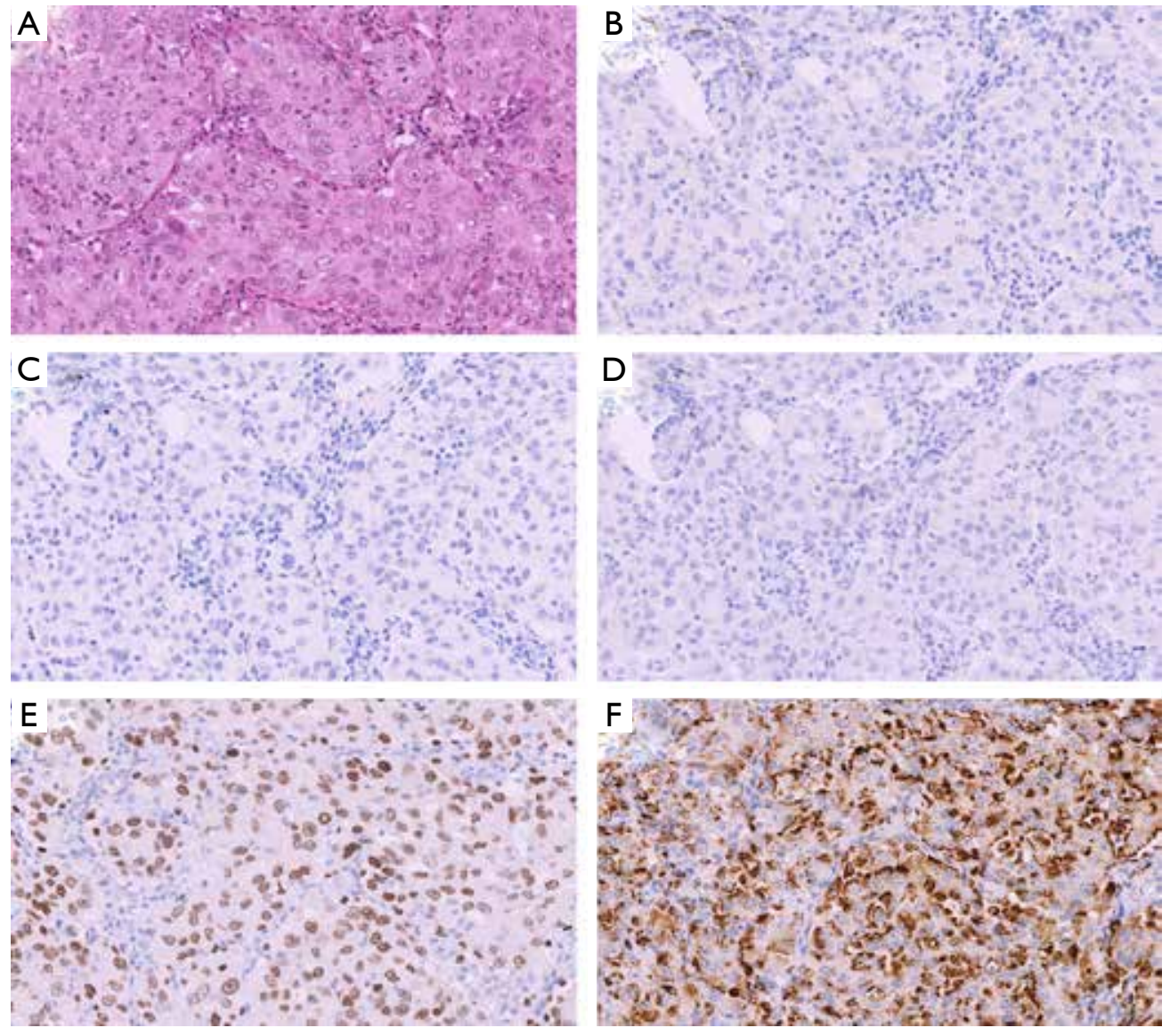

Figure 3 Representative immunohistochemical staining for solid predominant lung adenocarcinoma (A). The tumor cells were immunohistochemically stained negative for glypican-1 (B), p40 (C), and cytokeratin 5/6 (D) but were positive for thyroid transcription factor-1 (E) and napsin A (F) (hematoxylin and eosin $\times 200)$.

Table 2 Sensitivity, specificity, and diagnostic accuracy rate of immunohistochemical markers for the differential diagnosis of lung squamous cell carcinoma from lung adenocarcinoma

\begin{tabular}{lccc}
\hline Marker & $\begin{array}{c}\text { Sensitivity } \\
(\%)\end{array}$ & $\begin{array}{c}\text { Specificity } \\
(\%)\end{array}$ & $\begin{array}{c}\text { Diagnostic accuracy } \\
(\%)\end{array}$ \\
\hline Glypican-1 (+) & 100.0 & 96.7 & 98.4 \\
p40 (+) & 100.0 & 91.7 & 95.9 \\
CK 5/6 (+) & 98.4 & 83.3 & 91.1 \\
TTF-1 (-) & 93.7 & 90.0 & 91.9 \\
Napsin A (-) & 96.8 & 81.7 & 89.4 \\
\hline
\end{tabular}

CK, cytokeratin; TTF-1, thyroid transcription factor-1.

cell carcinoma from lung adenocarcinoma are shown in Table 2. The sensitivity (100\%), specificity (96.7\%), and diagnostic accuracy $(98.4 \%)$ of glypican-1 were similar to those of p40 and significantly better than those of CK 5/6.

\section{Discussion}

NSCLC accounts for the large number of lung cancer cases, approximately representing $85 \%$ of lung cancer cases. NSCLC mainly comprises two subtypes: lung adenocarcinoma and lung squamous cell carcinoma $(15,16)$. The accurate discrimination of the two main histological types of lung cancer is required for gene-targeted therapies. For example, mutations in epidermal growth factor receptor (EGFR) and anaplastic lymphoma kinase (ALK) fusions, which, respectively, lead to the treatment of EGFR and ALK tyrosine kinase inhibitors, are typically observed in lung adenocarcinoma and not in lung squamous cell carcinoma (17). The administration of bevacizumab to treat lung squamous cell carcinoma is contraindicated considering 
the risk of pulmonary hemorrhage (18). Here, we confirmed glypican-1 as an additional novel marker of lung squamous cell carcinoma differentiating from lung adenocarcinoma. Our data show that the sensitivity, specificity, and diagnostic accuracy of glypican-1 were similar or superior to those of other immunohistochemical markers of lung squamous cell carcinoma.

Glypican-1 is one of the six glycosylphosphatidylinositolanchored, cell surface heparan sulfate proteoglycans that acts as a growth factor signaling (19). The overexpression of glypican-1 has previously been reported in breast cancer (20), pancreatic cancer (21), and gliomas (22). On the contrary, a study assessing glypican-1 in lung squamous cell carcinoma has not been conducted yet. Recently, Hara et al. performed immunohistochemical analyses for glypican-1 using esophageal squamous carcinoma (23). In this study, the positive expression of glypican-1 was observed in $98.8 \%$ of esophageal squamous carcinoma specimens, with the basal layer of the esophageal specimens as the internal control. Additionally, our group has recommended glypican-1 as a novel positive marker of epithelioid mesothelioma, which showed negative expressions for lung adenocarcinoma (12). Glypican-1 expression was observed in the basal cells of the bronchial and bronchiolar epithelium and normal mesothelial cells as internal positive controls. These expressions were similar to the expressions of $\mathrm{p} 40$, CK $5 / 6$, and p63 in lung squamous cell carcinoma. Thus, we assumed the positive expression of glypican-1 for lung squamous cell carcinoma and hypothesized that glypican-1 is a novel positive marker of lung squamous cell carcinoma.

In the present study, we first investigated the microarray dataset (14) to evaluate the gene expression of glypican-1 in lung squamous cell carcinoma. GPC1 was identified as the differentially expressed gene in lung squamous cell carcinoma compared with lung adenocarcinoma. We also confirmed the mRNA transcripts of keratin (KRT) 6A, KRT6B, KRT5, and tumor protein p63 (TP63) were remarkably upregulated in lung squamous cell carcinoma. KRTs and TP63 are known to code CK 5/6 and p63, respectively.

Immunohistochemistry was performed in poorly differentiated lung squamous cell carcinoma and solid lung adenocarcinoma. We adopted anti-glypican-1 antibody (rabbitpolyclonal, 1:250, Proteintech, Cat\# 16700-1-AP, RRID:AB 1851168), which we and Saito et al. used in the previous study $(12,24)$, respectively. Well-differentiated types were excluded since, in clinical situations, immunohistochemistry was mainly used for cases that are difficult to discriminate, namely, poorly differentiated cases. The sensitivity and specificity of glypican-1 expression for the differentiation of lung squamous cell carcinoma from lung adenocarcinoma were $100 \%$ and $96.7 \%$, respectively. The sensitivities of p 40 and CK 5/6 for the identification of lung squamous cell carcinoma were also significantly high, which were within the reported ranges of $93-100 \%$ for $\mathrm{p} 40$ and $94-98 \%$ for CK $5 / 6(8,11,25-30)$. The specificities of p 40 and CK 5/6 were relatively high (91.7\% and $83.3 \%$, respectively). These results were within the reported ranges of $85-100 \%$ for p 40 and $78-99 \%$ for CK $5 / 6$ $(8,11,25-30)$. Based on previous studies, the diagnostic accuracy of p40 was the highest among the existing positive markers of lung squamous cell carcinoma. However, the sensitivity and specificity of glypican- 1 were comparable to those of $\mathrm{p} 40$ expression and higher to those of CK 5/6 expression.

In our study, the diagnostic accuracy rate of glypican-1 expression (98.4\%) was higher than that of $\mathrm{p} 40$ expression $(95.9 \%)$. However, it cannot be certainly concluded that glypican-1 is the superior immunohistochemical marker for lung squamous cell carcinoma. The evaluation of $\mathrm{p} 40$ positivity is easier than that of glypican-1 positivity for its nuclear staining patterns, preventing diagnostic discrepancies for surgical pathology. In order to identify lung squamous cell carcinoma, it is important to differentiate it from malignant mesothelioma $(31,32)$. Tatsumori et al. reported the high sensitivity and specificity of p40 staining for differentiating lung squamous cell carcinoma from malignant mesothelioma (27). We recently found p40 expression in only approximately $5 \%$ of cases of epithelioid mesothelioma $(11,33)$. However, since we proposed glypican-1 as a novel positive marker of epithelioid mesothelioma (12), glypican-1 is unable to differentiate between lung squamous cell carcinoma and malignant mesothelioma. Moreover, glypican-1 is not useful for distinguishing specific metastatic lung cancers from lung squamous cell carcinoma because of the glypican-1 overexpression for breast cancer (20), pancreatic cancer (21), and gliomas (22).

Only 2 out of $60(3.3 \%)$ lung adenocarcinoma cases were positive for glypican-1, both showing focal expression with 1+ immunohistochemical score (Figure S1). Both cases were negative for $\mathrm{p} 40$ and one case also showed positive CK5/6 expression with $2+$ immunohistochemical score. Both cases were also positive for TTF-1 and napsin A.

On the contrary, $5(8.3 \%)$ lung adenocarcinoma cases were positive for $\mathrm{p} 40$. Previous studies have also reported the 440 positive expression of lung adenocarcinoma. Bishop et al. (8), Tran et al. (29), and Kadota et al. (28), respectively, 
found $3 \%, 4 \%$, and $15 \%$ of lung adenocarcinoma with p40 positivity, although all of them showed focal positivity for $\mathrm{p} 40$. Consistent with previous reports, in our study, the immunohistochemical scores of all 5 (8.3\%) lung adenocarcinoma cases with $\mathrm{p} 40$ positivity were $1+$, and all of them had diffuse positivity for TTF-1 (Figure S2). There was no overlap of the expression of p40 and glypican- 1 in these 7 cases.

In conclusion, glypican-1 is considered an additional novel positive marker for lung squamous cell carcinoma for the differentiation from lung adenocarcinoma considering its significantly high sensitivity and specificity. We hypothesize that glypican-1 will assist in accurate discrimination even in cases that are difficult to differentiate, such as poorly differentiated lung squamous cell carcinoma and solid predominant adenocarcinoma. Further validation in other laboratories is required to support our findings.

\section{Acknowledgments}

We thank Ms. Yukari Go and Mr. Tatsuya Nakagawa of Hiroshima University for their excellent technical assistance and Ms. Naomi Fukuhara for her administrative support. Funding: This study was supported by JSPS KAKENHI Grant Number 17K08742.

\section{Footnote}

Reporting Checklist: The authors have completed the MDAR reporting checklist. Available at http://dx.doi.org/10.21037/ tlcr-20-857

Data Sharing Statement: Available at http://dx.doi. org/10.21037/tlcr-20-857

Peer Review File: Available at http://dx.doi.org/10.21037/ tlcr-20-857

Conflicts of Interest: All authors have completed the ICMJE uniform disclosure form (available at http://dx.doi. org/10.21037/tlcr-20-857). The authors have no conflicts of interest to declare.

Ethical Statement: The authors are accountable for all aspects of the work in ensuring that questions related to the accuracy or integrity of any part of the work are appropriately investigated and resolved. This study was performed in accordance with the declaration of Helsinki (as revised in 2013). This study was conducted in accordance with the "Ethics Guidelines for Human Genome/Gene Research" enacted by the Japanese government and approved by the institutional ethics review committee (Hiroshima University E-1347).

Open Access Statement: This is an Open Access article distributed in accordance with the Creative Commons Attribution-NonCommercial-NoDerivs 4.0 International License (CC BY-NC-ND 4.0), which permits the noncommercial replication and distribution of the article with the strict proviso that no changes or edits are made and the original work is properly cited (including links to both the formal publication through the relevant DOI and the license). See: https://creativecommons.org/licenses/by-nc-nd/4.0/.

\section{References}

1. Bray F, Ferlay J, Soerjomataram I, et al. Global cancer statistics 2018: GLOBOCAN estimates of incidence and mortality worldwide for 36 cancers in 185 countries. CA Cancer J Clin 2018;68:394-424.

2. Siegel R, Ma J, Zou Z, et al. Cancer statistics, 2014. CA Cancer J Clin 2014;64:9-29.

3. Takamochi K, Ohmiya H, Itoh M, et al. Novel biomarkers that assist in accurate discrimination of squamous cell carcinoma from adenocarcinoma of the lung. BMC Cancer 2016;16:760.

4. Travis WD, Noguchi $M$, Yatabe $Y$, et al. Adenocarcinoma. In: Travis WD, Brambilla E, Burke AP, et al. WHO Classification of Tumours of the Lung, Pleura, Thymus and Heart. Lyon: IARC Press, 2015:26-37.

5. Tsao MS, Brambilla E, Nicholson AG, et al. Squamous cell carcinoma. In: Travis WD, Brambilla E, Burke AP, et al. WHO Classification of Tumours of the Lung, Pleura, Thymus and Heart. Lyon: IARC Press, 2015:51-5.

6. Pelosi G, Sonzogni A, Viale G. The classification of lung carcinoma: time to change the morphology-based approach? Int J Surg Pathol 2010;18:161-72.

7. Rekhtman N, Ang DC, Sima CS, et al. Immunohistochemical algorithm for differentiation of lung adenocarcinoma and squamous cell carcinoma based on large series of whole-tissue sections with validation in small specimens. Mod Pathol 2011;24:1348-59.

8. Bishop JA, Teruya-Feldstein J, Westra WH, et al. $\mathrm{p} 40$ (DeltaNp63) is superior to $\mathrm{p} 63$ for the diagnosis of pulmonary squamous cell carcinoma. Mod Pathol 2012;25:405-15. 
9. Kriegsmann K, Cremer M, Zgorzelski C, et al. Agreement of CK5/6, p40, and p63 immunoreactivity in non-small cell lung cancer. Pathology 2019;51:240-5.

10. Affandi KA, Tizen NMS, Mustangin M, et al. p40 Immunohistochemistry Is an Excellent Marker in Primary Lung Squamous Cell Carcinoma. J Pathol Transl Med 2018;52:283-9.

11. Mawas AS, Amatya VJ, Kushitani K, et al. MUC4 immunohistochemistry is useful in distinguishing epithelioid mesothelioma from adenocarcinoma and squamous cell carcinoma of the lung. Sci Rep 2018;8:134.

12. Amatya VJ, Kushitani K, Kai Y, et al. Glypican-1 immunohistochemistry is a novel marker to differentiate epithelioid mesothelioma from lung adenocarcinoma. Mod Pathol 2018;31:809-15.

13. Lilo MT, Allison D, Wang Y, et al. Expression of P40 and P63 in lung cancers using fine needle aspiration cases. Understanding clinical pitfalls and limitations. J Am Soc Cytopathol 2016;5:123-32.

14. Tarca AL, Lauria M, Unger M, et al. Strengths and limitations of microarray-based phenotype prediction: lessons learned from the IMPROVER Diagnostic Signature Challenge. Bioinformatics 2013;29:2892-9.

15. Halliday PR, Blakely CM, Bivona TG. Emerging Targeted Therapies for the Treatment of Non-small Cell Lung Cancer. Curr Oncol Rep 2019;21:21.

16. Perez-Moreno P, Brambilla E, Thomas R, et al. Squamous cell carcinoma of the lung: molecular subtypes and therapeutic opportunities. Clin Cancer Res 2012;18:2443-51.

17. Cancer Genome Atlas Research N. Comprehensive genomic characterization of squamous cell lung cancers. Nature 2012;489:519-25.

18. Johnson DH, Fehrenbacher L, Novotny WF, et al. Randomized phase II trial comparing bevacizumab plus carboplatin and paclitaxel with carboplatin and paclitaxel alone in previously untreated locally advanced or metastatic non-small-cell lung cancer. J Clin Oncol 2004;22:2184-91.

19. Lamoureux F, Baud'huin M, Duplomb L, et al. Proteoglycans: key partners in bone cell biology. Bioessays 2007;29:758-71.

20. Matsuda K, Maruyama H, Guo F, et al. Glypican-1 is overexpressed in human breast cancer and modulates the mitogenic effects of multiple heparin-binding growth factors in breast cancer cells. Cancer Res 2001;61:5562-9.

21. Kleeff J, Ishiwata T, Kumbasar A, et al. The cell-surface heparan sulfate proteoglycan glypican-1 regulates growth factor action in pancreatic carcinoma cells and is overexpressed in human pancreatic cancer. J Clin Invest 1998;102:1662-73.

22. Su G, Meyer K, Nandini CD, et al. Glypican-1 is frequently overexpressed in human gliomas and enhances FGF-2 signaling in glioma cells. Am J Pathol 2006;168:2014-26.

23. Hara H, Takahashi T, Serada S, et al. Overexpression of glypican-1 implicates poor prognosis and their chemoresistance in oesophageal squamous cell carcinoma. Br J Cancer 2016;115:66-75.

24. Saito T, Sugiyama K, Hama S, et al. High Expression of Glypican-1 Predicts Dissemination and Poor Prognosis in Glioblastomas. World Neurosurg 2017;105:282-8.

25. Nonaka D. A study of DeltaNp63 expression in lung nonsmall cell carcinomas. Am J Surg Pathol 2012;36:895-9.

26. Pelosi G, Rossi G, Cavazza A, et al. DeltaNp63 (p40) distribution inside lung cancer: a driver biomarker approach to tumor characterization. Int J Surg Pathol 2013;21:229-39.

27. Tatsumori T, Tsuta K, Masai K, et al. p40 is the best marker for diagnosing pulmonary squamous cell carcinoma: comparison with p63, cytokeratin 5/6, desmocollin-3, and sox2. Appl Immunohistochem Mol Morphol 2014;22:377-82.

28. Kadota K, Nitadori J, Rekhtman N, et al. Reevaluation and reclassification of resected lung carcinomas originally diagnosed as squamous cell carcinoma using immunohistochemical analysis. Am J Surg Pathol 2015;39:1170-80.

29. Tran L, Mattsson JS, Nodin B, et al. Various Antibody Clones of Napsin A, Thyroid Transcription Factor 1, and p40 and Comparisons With Cytokeratin 5 and p63 in Histopathologic Diagnostics of Non-Small Cell Lung Carcinoma. Appl Immunohistochem Mol Morphol 2016;24:648-59.

30. Micke P, Mattsson JS, Djureinovic D, et al. The Impact of the Fourth Edition of the WHO Classification of Lung Tumours on Histological Classification of Resected Pulmonary NSCCs. J Thorac Oncol 2016;11:862-72.

31. Attanoos RL, Gibbs AR. 'Pseudomesotheliomatous' carcinomas of the pleura: a 10-year analysis of cases from the Environmental Lung Disease Research Group, Cardiff. Histopathology 2003;43:444-52.

32. Ordonez NG. The diagnostic utility of immunohistochemistry in distinguishing between epithelioid mesotheliomas and squamous carcinomas of the lung: a comparative study. Mod Pathol 
2006;19:417-28.

33. Kushitani K, Amatya VJ, Okada Y, et al. Utility and pitfalls of immunohistochemistry in the differential diagnosis between epithelioid mesothelioma and poorly differentiated lung squamous cell carcinoma. Histopathology 2017;70:375-84.

Cite this article as: Kai Y, Amatya VJ, Kushitani K, Kambara T, Suzuki R, Fujii Y, Tsutani Y, Miyata Y, Okada M, Takeshima Y. Glypican-1 is a novel immunohistochemical marker to differentiate poorly differentiated squamous cell carcinoma from solid predominant adenocarcinoma of the lung. Transl Lung Cancer Res 2021;10(2):766-775. doi: 10.21037/tlcr-20-857 

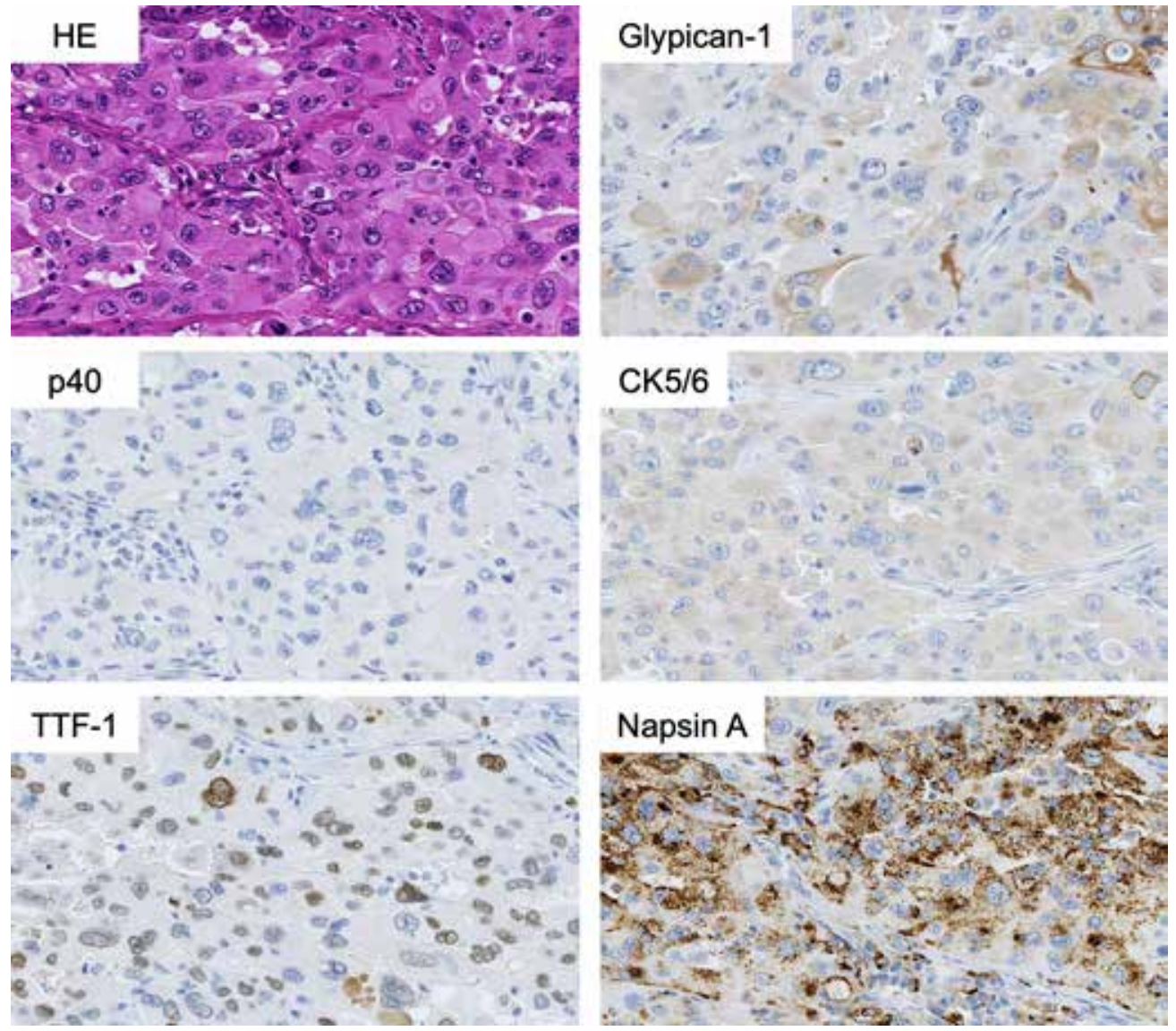

Figure S1 One exceptional case of glypican-1-positive solid lung adenocarcinoma (1+). The tumor cells were immunohistochemically stained negative for $\mathrm{p} 40$ and cytokeratin $5 / 6$ but were positive for thyroid transcription factor- $1(3+)$, and napsin $\mathrm{A}(3+)$. 

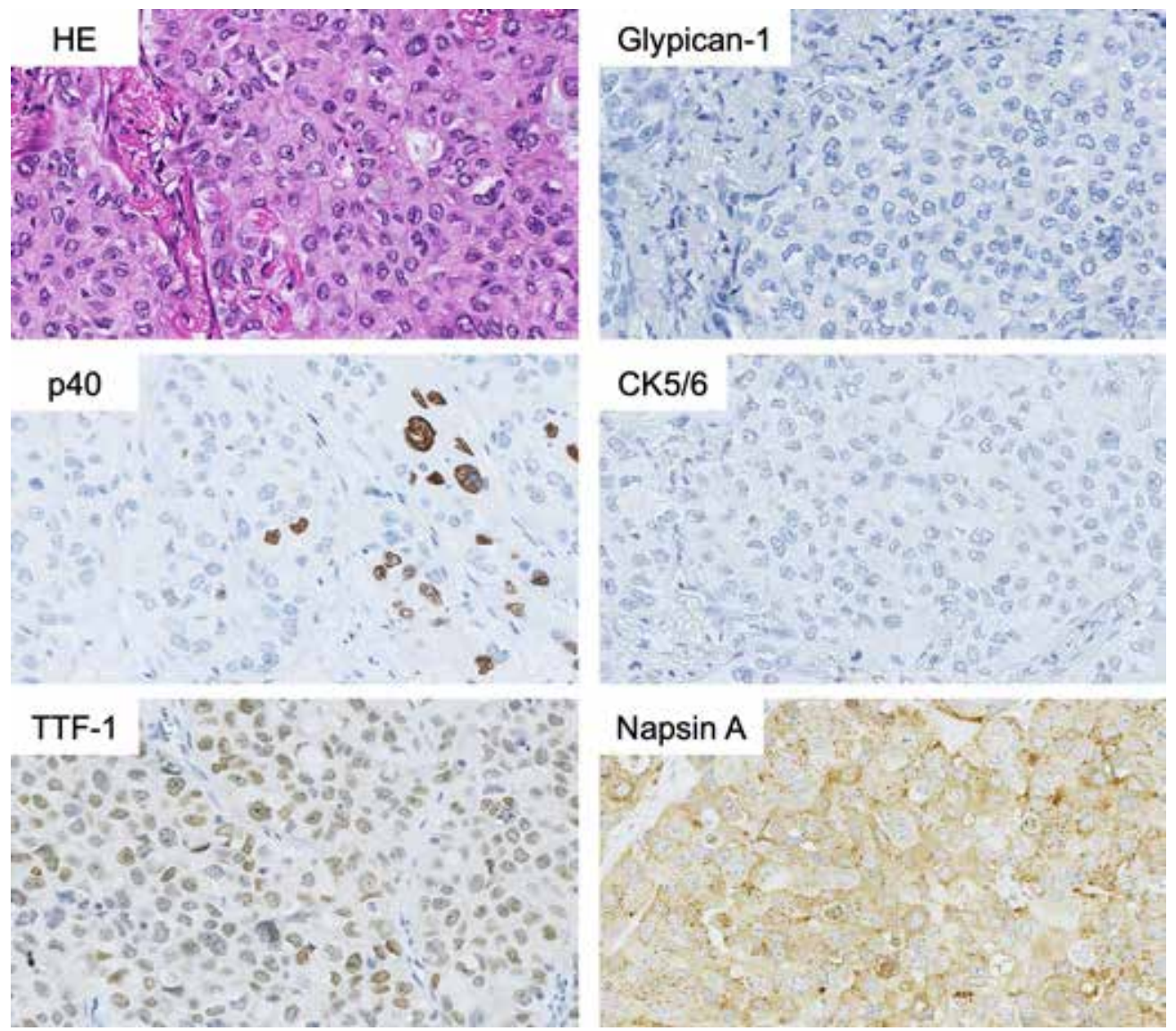

Figure S2 One exceptional case of p40-positive solid lung adenocarcinoma (1+). The tumor cells were immunohistochemically stained negative for glypican-1 and cytokeratin 5/6 but were positive for thyroid transcription factor-1 (2+) and napsin A (3+). 